anaesthetist 8 agreed with many of his colleagues (fig 2 ) because he deviated least from the consensus. No doubt anaesthetists 1 , 5 , and 10 agreed well with each other because they were all optimists ( $\kappa$ for anaesthetist 1-anaesthetist 5 was 0.55 ), and anaesthetist 6 agreed so poorly because of his extreme pessimism.

The use of a maximum likelihood technique to derive a consensus estimate of fitness for each patient made it possible to compare judgments based on increasing amounts of information (levels A, B, and C). An important point emerges from this. Patients who are thought to be perfectly fit on the basis of simple questions usually prove to be so after the traditional preoperative history and investigations. This suggests that a questionnaire might be developed for use in surgical outpatients to select patients for day surgery. But it might be of little practical use if it had to be assessed by a group of anaesthetists to determine the consensus category. If it is accepted that the difference between category 1 and 2 is of little clinical significance, then every anaesthetist was correct on $96 \%$ of occasions when level A information was used. The exact fitness of the other patients would be less important because they would still require careful examination so that the most appropriate anaesthetic technique could be chosen. The most important function of a questionnaire would therefore be to alert the anaesthetist to possible problems, when further investigation could be undertaken as an outpatient.

\section{References}

${ }^{1}$ Cohen J. A coefficient of agreement for nominal scales. Educ and Psychol Meas $1960 ; 20: 37-46$.

2 Cohen J. Weighted kappa: nominal scale agreement with provision for scaled disagreement or partial credit. Psychol Bull 1968;70:213-20.

${ }^{3}$ Fleiss JL. Measuring nominal scale agreement among many raters. Psychol Bull 1971;76:378-82.

4 Dawid AP and Skene AM. Maximum likelihood estimation of observer error rates using EM algorithm. Applied Statistics 1979;28:20-8.

${ }^{5} \mathrm{McNeil}$ BJ, Keeler E, Adelstein SJ. Primer on certain elements of medical decision making. $N$ Engl f Med 1975;293:211-5.

${ }^{6}$ Goldman L, Caldera DL, Nussbaum SR, et al. Multifactorial index of cardiac risk in non-cardiac surgical procedures. N Engl f Med 1977; $297: 845-50$.

7 Owens WD, Felts JA, Spitznagel EL. ASA Physical Status Classifications. Anesthesiology 1978;49:239-43.

${ }^{8}$ Keats AS. The ASA Classification of Physical Status-a recapitulation. Anesthesiology 1978;49:233-6.

(Accepted 27 November 1979)

\title{
Prognostic importance of specific immunoreactivity in occupational bladder cancer
}

\author{
S KUMAR, G TAYLOR, P WILSON, WENDY HURST
}

\section{Summary and conclusions}

Sixty-eight workers with a history of exposure to a bladder carcinogen were followed up to see whether changes in lymphocyte immunoreactivity to a bladdercancer-cell target were predictive of the development of neoplasia of the urothelium. A twofold or greater increase in reactivity was strongly associated with the development of abnormal urinary cytology suggestive or indicative of malignant change. Changes in immunoreactivity to a non-bladder-cancer-cell target did not have this association.

The findings support the possibility that changes in lymphocyte immunoreactivity may be used to predict the onset of bladder cancer in people exposed to bladder carcinogens.

\section{Introduction}

In an earlier study we compared lymphocyte reactivity against a bladder-cancer target cell in a group of workers exposed to bladder carcinogens with that in normal people and patients with bladder cancer. ${ }^{1}$ Equivalent increases in reactivity were found in clinically normal carcinogen-exposed workers and

University Department of Bacteriology and Virology, Manchester S KUMAR, MVETSC, PHD, (head of paediatric oncology laboratory, Christie Hospital and Holt Radium Institute, Withington, Manchester M20 9BX) $P$ WILSON, PHD, postdoctoral fellow

WENDY HURST, BSC, postgraduate student

Appalachian Laboratory for Occupational Safety and Health, Morgantown, West Virginia 26505, USA

G TAYLOR, MD, (present address: Wasau Medical Centre, Wasau, Wisconsin 54401, USA) patients with bladder cancer when compared with the normal controls. The augmented reactivity was considered to be specific for bladder cancer, as differences in group reactivity against a non-bladder-cancer tumour cell were not found. Furthermore, increases in reactivity in the worker group were related to the degree of exposure to bladder carcinogens and also to the development of abnormal urinary cytology suggestive of early malignant change in the urothelium. We have now followed up the worker group to see whether serial changes in lymphocyte reactivity with time help to predict the development of bladder cancer in individual workers.

\section{Subjects and methods}

Chemical workers-Of the original group of 93 workers, 68 were available for continued study. All had been exposed to either $\alpha-$ naphthylamine containing 4-8\% $\beta$-naphthylamine or "pure" $\beta$ naphthylamine before 1952. Urinary cytology with Papanicolaou staining was carried out six-monthly and blood samples for lymphocytotoxicity studies taken at about yearly intervals over four years.

Target and effector cells-The bladder-cancer cell (FB) and control target cell (osteosarcoma) were the same as used in our earlier study. ${ }^{1}$ They were available stored in liquid nitrogen in aliquots of $1 \mathrm{ml}$ containing about $3 \times 10^{6}$ cells in medium 199 with $30 \%$ fetal calf serum and $10 \%$ dimethyl sulphoxide. To avoid the possibility of antigenic change we did not passage cells during the study. Effector lymphocytes were prepared from $20 \mathrm{ml}$ defibrinated venous blood by the method of Coulson and Chalmers ${ }^{2}$ with a phagocyte-removal step using carbonyl iron powder and magnetic separation. The cells were washed three times in Hanks's balanced salt solution containing $5 \%$ fetal calf serum.

Microcytotoxicity tests-We used two procedures for testing microcytotoxicity. The first was based on the method of Takasugi and Klein $^{3}$ as modified by Taylor et al. ${ }^{1}$ The second method used ${ }^{75} \mathrm{Se}-$ selenomethionine incorporation to measure residual cells, as described by Brooks et al. ${ }^{4}$ With each method five lymphocyte :target-cell ratios were set up, each in replicates of eight. The ratio of lymphocytes to 
target cells needed to produce a $50 \%$ reduction in target cells as compared with media-only controls $\left(\mathrm{LD}_{50}\right)$ was calculated with a least-squares fit of the data for each ratio. With the osteosarcoma microcytotoxicity determinations an $\mathrm{LD}_{25}$ ratio was calculated, since a $50 \%$ kill was often not achieved with the maximum lymphocyte:target-cell ratio used $(1200: 1)$.

\section{Results}

Comparison of results using visual counting with the ${ }^{75} \mathrm{Se}-$ selenomethionine method of determining residual target cells showed excellent agreement (figure). Later only the selenomethionine method was used, with resultant savings in time and manpower. To measure change in lymphocyte reactivity the ratio of the worker's initial $\mathrm{LD}_{50}$ to the second determination of $\mathrm{LD}_{50}$ about one year later was calculated.

During the period of study eight workers developed abnormal urinary cytology, as defined by a change to grade III, IV, or V on Papanicolaou staining. Changes in $\mathrm{LD}_{50}{ }^{1}: \mathrm{LD}_{50}{ }^{2}$ against bladdercancer-cell $\mathrm{FB}$ and $\mathrm{LD}_{25}{ }^{1}: \mathrm{LD}_{25}{ }^{2}$ against the osteogenic sarcoma cell are shown in table I for these workers and for those who remained in grade I or II during the study. A statistically significant increase in lymphocyte reactivity, as indicated by a rising $\mathrm{LD}_{50}{ }^{1}: \mathrm{LD}_{50}{ }^{2}$, occurred against the bladder-cancer-cell target in those workers who developed abnormal urinary cytology as compared with their fellow workers. Changes in reactivity to the osteosarcoma cell were often observed but did not differ significantly in the two groups, both having a median value of no change. In the group with abnormal urinary cytology only one worker showed an increase in reactivity to the

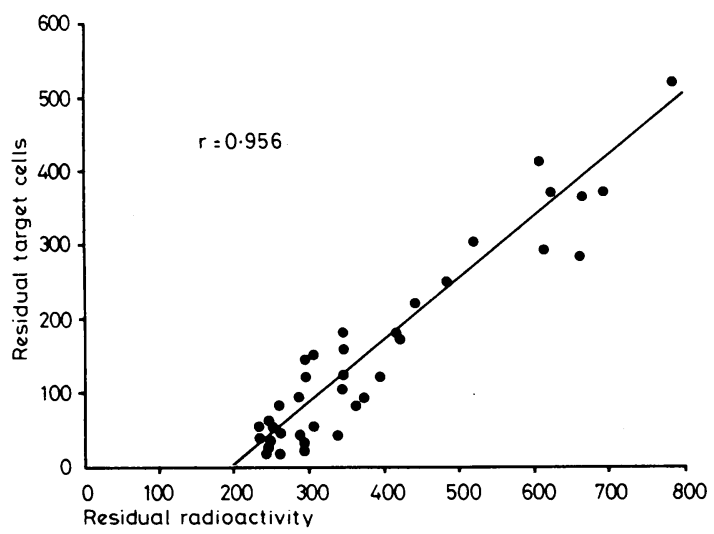

Correlation between number of residual target cells (visual) and residual radioactivity ( ${ }^{75} \mathrm{Se}$-selenomethionine).

TABLE I-Changes in lymphocyte reactivity to bladder-cancer and osteosarcoma target cells in workers with and without abnormal urinary cytology :

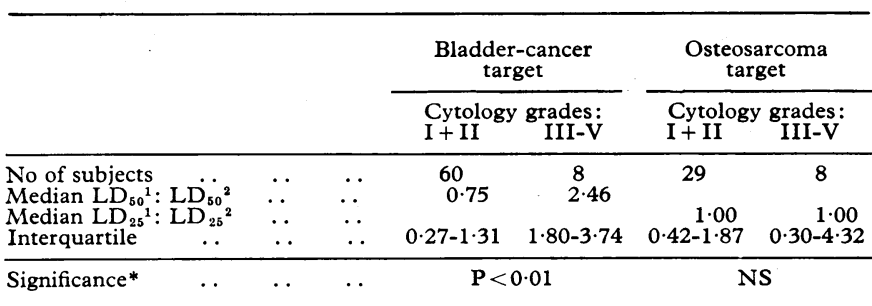

*Mann-Whitney test.

NS $=$ Not significant.

TABLE II-Change in $L D_{50}^{1}: L D_{50}^{2}$ against bladder-cancer target cells and abnormal urinary cytology in individual workers

\begin{tabular}{|c|c|c|c|}
\hline & \multicolumn{2}{|c|}{ Decrease to: } & \multirow{2}{*}{$\begin{array}{l}\text { Increase of } \\
\geqslant 1.0 \text { or no } \\
\text { change }\end{array}$} \\
\hline & $\leqslant 0.5$ & $0.51-0.99$ & \\
\hline $\begin{array}{l}\text { No with abnormal cytology } \\
\text { No with normal cytology }\end{array}$ & $\begin{array}{l}6 \\
7\end{array}$ & $\begin{array}{r}1 \\
14\end{array}$ & $\begin{array}{r}1 \\
39\end{array}$ \\
\hline
\end{tabular}

osteosarcoma target, whereas seven of the eight had increases in reactivity to the bladder-cancer cell. Table II shows the individual changes in reactivity to the bladder-cancer cell.

\section{Discussion}

In our earlier study $^{1}$ we showed that increased immunoreactivity against a bladder-cancer target cell was associated with factors that are known epidemiologically to predict increased risk of developing bladder cancer. Thus increased immunoreactivity was highest in workers most heavily exposed to known bladder carcinogens. We suggested that measuring immunoreactivity to bladder-cancer cells might provide a means of identifying a very-high-risk group of workers among the high-risk group and that follow-up studies would show if the method could be used for surveillance of individual workers.

The results of follow-up showed a strong association between an increase in reactivity towards bladder-cancer target cells on repeated testing and the development of abnormal urinary cytology suggestive or indicative of malignant change in the urothelium. An association was not found between the development of abnormal urinary cytology and changes in immunoreactivity against a non-bladder-cancer target cell, suggesting that the changes in reactivity observed were tumour-specific.

We used an arbitrary criterion of a doubling of reactivity to analyse the results in individual workers. This degree of change occurred in 13 out of 68 workers. Of these, $6(46 \%)$ had developed abnormal urinary cytology while only two out of 55 workers who did not show increases in reactivity of twice or greater had abnormal cytology. Both workers had such low $\mathrm{LD}_{50}$ ratios when first measured that it was very unlikely that we could detect an increase of this magnitude when retested. One remained static at this low ratio and the other decreased to the lowest ratio we could detect without reaching the factor of two. Because of the close association between individual workers we are paying close attention to follow-up of the seven currently with normal urinary cytology who showed increases in reactivity. Conversely, maintenance of a relatively static immunoreactivity to bladder-cancer targets apparently carried a good prognosis, at least over the relatively short period of our study. If the two workers with very low $\mathrm{LD}_{50}$ ratios on first testing are excluded then no worker in this group developed abnormal cytology. The findings tend to confirm our suggestion that immunoreactivity may be used for surveillance; however, follow-up over much longer than four years will be required to prove its utility.

This study was supported through National Bladder Cancer Project by National Cancer Institute Grant. We thank Drs J Gardiner, W Taylor, G H Shaw and Alyn Evans, medical departments of organics division, ICI Ltd.

ADDENDUM-Since submitting the manuscript, we have detected doublings of lymphocytotoxicity in four of a further 16 chemical workers with currently normal urine cytology. These four like the other seven (table II) will need close attention and follow-up.

\section{References}

1 Taylor G, Kumar S, Brenchley P, Wilson P, Costello B, Shaw GH. Immunosurveillance in pre-malignant occupational bladder disease. Int $\mathcal{F}$ Cancer $1979 ; 23: 487-93$.

2 Coulson AS, Chalmers DG. Response of human blood lymphocytes to tuberculosis PPD in tissue culture. Immunology 1967;12:417-29.

3 Takasugi $\mathrm{M}$, Klein E. A microassay for cell mediated immunity. Transplantation 1970;9:217-9.

${ }^{4}$ Brooks CG, Rees RC, Robins RA. Studies on the microcytotoxicity tests Part II. The uptake of amino acids ( ${ }^{3} \mathrm{H}$-leucine or ${ }^{75} \mathrm{Se}$-methionine) but not nucleosides $\left({ }^{3} \mathrm{H}\right.$-thymidine or $\left.{ }^{125} 1-\mathrm{UdR}\right)$ or ${ }^{51} \mathrm{Cr}_{2} \mathrm{O}_{4}$ provides a direct and quantitative measure of target cell survival in the presence of lymphoid cells. F Immunol Methods 1978;21:111-24. 